\title{
Arbor
}

\section{La protección jurídica de las ciudades históricas}

\author{
José Luis Álvarez Álvarez
}

Arbor CLXX, 671-672 (Noviembre-Diciembre 2001), 429-460 pp.

\section{Introducción}

La Historia del hombre es muy reciente y señalar el momento del paso a la prehistoria de la historia no es nada fácil. Se dice que la Historia es la ciencia que estudia la evolución de la cultura humana y que la primera Historia que se escribe es la de Herodoto en el siglo $\mathrm{V}$ antes de Cristo, que ya era un relato e investigación de las costumbres y vidas de todos los pueblos civilizados o bárbaros conocidos entonces por los griegos. Después se citan las historias de Polibio (siglo II a.C.), Diodoro y Estrabón. Es solo en el siglo XIX cuando empieza a hablarse de la Prehistoria como una ciencia distinta y se cita al francés Boucher de Perthes (1788-1868) como su fundador, ya en pleno siglo XIX, diferenciándose porque la prehistoria no se basa en documentos sino en la utilización de la Geología, la Paleontología y en el estudio de los restos, y trabajos en piedra o metal, y en los hábitats y restos de aquellos hombres.

Pero ir más allá para distinguir la Historia de la Prehistoria ni es fácil ni pacifico, ni es tarea que nos competa a nosotros. Pero es indudable que la aparición de la ciudad es ya un acontecimiento histórico que se puede remontar o a la mítica Jericó de 6000 años antes de Cristo, o a las ciudades anteriores a la era cristiana de China, India, Mesopotamia, Egipto y finalmente a las mediterráneas: Atenas, Esparta, Roma, ya plenamente históricas, y que podemos hablar sin ninguna duda de ciudades milenarias.

En España tenemos testimonios históricos de muchas ciudades anteriores a la era cristiana: Ampurias, Sagunto., Numancia, Cartagena, 


\section{José Luis Álvarez Álvarez}

Cádiz, son ejemplos clarísimos, y ciudades milenarias, habitadas ininterrumpidamente desde hace más de mil años hay muchas más: Sevilla, Córdoba, Málaga, Mérida, León, Tarragona, Toledo, Granada, Zaragoza, son quizá las más conocidas o famosas pero hay muchas otras.

Hablar de ciudades milenarias en España es absolutamente lícito, pero en verdad y desde el punto de vista de la preocupación por su conservación e interés y de la preservación de la historia y sus características es mejor extender la referencia no solo a las ciudades milenarias, sino a las ciudades históricas, aquellas que tienen un interés especial por su subsistencia y evolución a través de los siglos aunque no lleguen al milenio.

Hoy, es opinión general al menos desde el punto de vista de la Cultura, de la Historia y del Arte que esas ciudades que han llegado hasta nosotros son un patrimonio de todos que merece un tratamiento especial, por su interés histórico y artístico, por ser un testimonio de lo que ha sido la vida y la evolución del hombre y por razones incluso económicas y convivenciales que iremos desgranando a través de estas páginas. Pero si esta actitud y reconocimiento repercute en su favor hay muchas otras circunstancias que ponen en peligro la subsistencia de esas ciudades, o de su personalidad y esencia. Frente al respeto a su historia se alzan los intereses que ofrecen su posibilidades de desarrollo; frente a su interés cultural se alza la multiplicación en muchos casos, de sus habitantes; frente al respeto a su carácter, naturalmente antiguo, se alzan las exigencias de la modernidad.

Todo ello se hace mucho más inteligible cuando ponemos los ojos en muchas de esas ciudades que han resistido con graves dificultades el «progreso» de los dos últimos siglos. Estos han traído aspectos tan positivos como la revolución industrial, el incremento de la población en forma progresiva, casi geométrica, por el aumento de la natalidad y de la esperanza de vida, la motorización con sus exigencias de nuevas y más amplias vías, la edificación en altura, el traslado de gran parte de la población del campo a la ciudad. Pero esos indudables "progresos» han tratado de imponer sus necesidades con tanta urgencia y fuerza que muchas veces han incidido negativa y gravemente sobre las ciudades históricas. Y ese fenómeno de urbanización y modernización que empieza en el siglo XIX y se acentúa enormemente en el XX, ha producido evidentes daños en los aspectos culturales, artísticos e históricos de esas ciudades, de forma que el progreso se ha hecho sin el debido cuidado o respeto a un patrimonio valiosísimo. Las primeras reacciones frente a este riesgo se producen en Gran Bretaña en el siglo XIX, y en disposiciones aisladas y sin suficiente fuerza en los demás países desarrollados con ciudades 
La protección jurídica de las ciudades históricas

milenarias hasta una época muy reciente prácticamente la segunda mitad de este siglo que ahora acaba, en la que empiezan a dictarse normas eficaces para su protección. $Y$ lo que es más grave, a pesar de estas reacciones, todavía hoy se siguen produciendo enormes deterioros por razones de una u otra clase a las ciudades históricas.

Quizá por ello y para tratar el tema tal como hoy se presenta, sea bueno hacer un breve repaso histórico de los diversos intentos de poner de relieve el riesgo que sufren las viejas ciudades por las aparentes exigencias o conveniencias de la modernización.

\section{La aparición en la historia del principio de conservación del patrimonio arquitéctico}

La historia está hecha del éxito de grandes civilizaciones y su consiguiente desarrollo y caída. Para referirnos nada más a la historia europea y mediterránea, dejando de lado la de los países de Extremo Oriente, si repasamos a grandes saltos lo que ha pasado en la época histórica más reciente, es decir la que va de los 3000 años antes de Cristo hasta nuestros días, podemos citar una serie de imperios y culturas que empiezan por Mesopotamia, siguen en Egipto, Grecia y Roma y ya continúan en la evolución de Europa occidental.

Pues bien en toda la primera parte de esos cincuenta siglos hay una época muy larga en la que las grandes ciudades que existieron, prácticamente han desaparecido: Babilonia, Nínive, Tebas, Luxor, Tellel-Amarna, Alejandría, etc. Lo que queda de ellas son restos excepcionales que han subsistido por el enorme volumen de algunas de sus construcciones, que han resistido el paso del tiempo, el abandono y hasta haber servido de cantera para nuevas construcciones de muy inferior calidad. Y es ya en los siglos XIX y XX cuando empiezan a valorarse esos restos, ya no como ciudades vivas sino como testimonios de un pasado glorioso.

Cuando nos acercamos a las dos grandes culturas mediterráneas, mas próximas en el tiempo, Grecia y Roma el fenómeno es parecido. Cuando decae su poder e importancia, y a pesar de que sus más representativas ciudades no dejan de estar habitadas, se produce el fenómeno de que su decadencia hace olvidar su grandiosidad y el tiempo y el desprecio por la historia y sus realizaciones o sencillamente la incultura generalizada, hacen lo demás. De las fantásticas ciudades gloriosas de la cultura helénica vemos hoy, no lo que se ha conservado sino sencillamente lo que ha subsistido de sus monumentos mas notables y menos perecederos. Algunos templos o restos de ellos en Atenas, o 
en las ciudades más importantes de su cultura, en Asia Menor o en Sicilia: Efeso, Agrigento, Siracusa. Y de muchas de sus legendarias ciudades, Troya, Esparta, Corinto no queda rastro o puramente restos arqueológicos. Y todo ello porque no existía preocupación por conservar las glorias pasadas. Y es, repito en el siglo XVIII o XIX cuando con la Ilustración o el Renacintismo se vuelven los ojos a lo "Antiguo». Basta pensar como ejemplo en la tragedia que fue para toda la $\mathrm{Hu}-$ manidad que el Partenón que había permanecido entero a lo largo de los siglos, a pesar de la casi completa destrucción de Atenas, fuera utilizado como polvorín por los turcos y que una granada veneciana convirtiera en 1687 en ruinas lo que estaba conservado casi plenamente, y que después la incuria y la incultura destruyeran aun más las esculturas que probablemente Lord Elgin, a pesar de su discutible adquisición salvó de una ruina total.

Y si de Roma hablamos, no obstante su extraordinario poder tampoco supera su decadencia, a pesar de seguir siendo la cabeza de la Catolicidad, y tras el poder bárbaro y los siglos de la ignorancia que dieron en tierra no sólo con la vieja ciudad imperial sino con muchos de sus más notables edificios, hay que llegar a los siglos XIV y XV para empezar a atisbar las primeras reacciones en favor de la conservación, no de la vieja ciudad, sino de algunas muestras egregias de su esplendor.

Se ha dicho que el concepto de monumento histórico y la necesidad de su protección surge en Roma a principios del siglo XV, aunque como veremos hay antecedentes en el anterior. El Papa Martín V al reintegrarse a Roma tras el exilio de Avignon, quiere restituir a aquella ciudad desmanteladas su antiguo poder y prestigio, y empieza a reconocerse el valor de los monumentos, en ruinas, romanos. En el Trecento ya Petrarca en su poema «Africa» habla de la antigüedad como un ejemplo de virtud y belleza y los edificios antiguos adquieren un valor nuevo. También en ese mismo siglo Niccolo Niccoli, en la Florencia de 1380 se apasiona por la escultura antigua que busca en toda Italia y hace una colección que lega a Cosme de Medicis.

El Renacimiento es el punto de partida para una nueva concepción y respeto por lo antiguo y por la época clásica , que abre la posibilidad de reconocer que las ciudades tienen su propia vida y personalidad, pero aún así es curioso que al revés de lo que va a pasar en el siglo XIX y XX que demuestran un interés especial por el Patrimonio Arquitectónico, en los siglos XV y XVI, predomina el interés por las obras de arte muebles es decir sobre todo por la escultura clásica y si acaso por los monumentos o sus restos helénicos y romanos, pero 
no por la conservación de las ciudades como núcleos. Probablemente porque han pasado muchos siglos y porque las ciudades medievales no despiertan el interés necesario para conservarlas, por su modestia, materiales pobres y por el impulso de una renovación, cambio de modelos y admiración por el periodo clásico que el Renacimiento lleva consigo. $\mathrm{Y}$ que se desarrolla precisamente en la recuperación de la importancia de las ciudades que hace libres a sus habitantes superando el sistema de vasallaje o dependencia del señor de la tierra, propio de la larga época feudal europea. En las ciudades aparece una nueva clase, la burguesía que, fundada en la libertad de las personas y en el comercio permite que surja la importancia de la persona no por la cuna sino por la fortuna, o por sus capacidades. Esa nueva clase es la que en Flandes e Italia hace unas fortunas mobiliarias que le dan la potencia financiera necesaria para, sobre todo en Italia, apoderarse del gobierno de las ciudades y tratar luego de embellecerlas para reafirmar su poder económico con su potencia cultural.

En el Quatrocento la pasión por «lo antiguo» se desborda. Alberti estudia los edificios romanos no sólo como testigos de la Historia, sino como obras de arte y prepara un plan topográfico para restaurar la ciudad para el Papa Nicolás V, y en su «de re aedificatoria» manifiesta que los edificios de Roma son el fundamento de las reglas de la belleza arquitectónica.

Es en este principio del siglo XV cuando empiezan a aparecer las primeras normas de los pontífices defendiendo los monumentos y ruinas romanas. Martín V ordena la conservación de esos monumentos, y Eugenio IV en la década de los treinta, establece criterios de conservación y protección de los monumentos romanos. Son los papas los que impulsan los trabajos de conservación y Pio II Piccolomini, -que antes que Papa fue un famoso humanista y cuya historia personal es un magnifico ejemplo del humanismo, el amor por la cultura clásica y las virtudes y defectos renacentistas- publica en 1462 la bula titulada «Cum almam nostram Urbem» en la que «deseando conservar a Roma con su dignidad y esplendor» se propone desplegar «un cuidado vigilante» no sólo para conservar las iglesias, basílicas y lugares Santos de la ciudad, sino también para que las generaciones futuras encuentran en buen estado los edificios de la Antigüedad y sus ruinas. Para ello establece una serie de prohibiciones para evitar la demolición y degradación de los edificios antiguos, y bajo pena de excomunión y sanciones pecuniarias, prohibe a «todos, religiosos y laicos», demoler dañar o convertir en cal cualquier edificio o vestigio de lós edificios de la antigua Roma, aunque les pertenezcan en propiedád. 
Y más aún los Papas citados limpian y restauran las antigüedades, lo que no quita para que llevados de su impulso, los coleccionistas arranquen piezas y esculturas a los edificios antiguos o que se utilicen los mármoles del Coliseo para la construcción del nuevo San Pedro.

Naturalmente no es posible hacer aquí una historia del desarrollo y aumento del respeto a los monumentos históricos, pero es evidente que de la conservación de las obras de arte aisladas separadas se pasa a la preocupación y conservación de los monumentos como un todo y se empiezan a estudiar y describir estos y a defender su mantenimiento; en 1670 se publica en Inglaterra una obra de Aubrey sobre los «Monumenta británica» y ese país mantiene su postura de adelantado en la conservación de sus monumentos en todo el siglo XIX mientras que en el continente las leyes protectoras son mayoritariamente del siglo XX. La Sociedad de Anticuarios de Londres se funda en 1585 para «hacer progresar e ilustrar la historia y las antigüedades de Inglaterra». La Revolución francesa que tantos destrozos causó en los monumentos religiosos trajo también, a propuesta de Mirabeau y Talleyrand, la idea de crear una Comisión de Monumentos y clasificar estos. El concepto de monumento histórico se acuña ya con generalidad en el siglo XIX, y en su lugar citaremos las primeras normas españolas que se dan con ese fin.

Pero pasar de la defensa del monumento al concepto de patrimonio y a la defensa del pueblo o la ciudad como conjunto requiere muchos más tiempo. Haussman transforma París, arrasando barrios enteros y cuando se le critica se defiende distinguiendo entre monumentos dignos de conservarse y barrios degradados. Ruskin en Gran Bretaña defiende en cambio un proyecto de defensa del patrimonio urbano histórico e incluso de la ciudad histórica. Tarda mucho sin embargo en proclamarse la idea de la conservación de la ciudad como algo conjunto y no reducible a la suma de sus monumentos.

Ruskin alerta contra las intervenciones que rompen el tejido de las ciudades históricas y dice que es «la continuidad de sus casas modestas al borde de canales y calles, lo que convierte en un conjunto artístico ciudades como Venecia, Florencia, Rouen u Oxford». y afirma que, sin que fueran conscientes de ello sus habitantes y constructores, la ciudad ha jugado el papel de testimonio y monumento.

A esta concepción no le han faltado defensores y detractores. Entre los más famosos de los primeros está el vienés Camillo Sitte (1843-1903) que habla de la fealdad de las ciudades modernas y de la necesidad de conservar las ciudades históricas como un objeto raro, frágil y preciso para el arte y para la historia. Por su influencia se salvó la Grand-Place 
de Bruselas gracias a un alcalde, Charles Buls, seguidor de aquél que escribió en 1912 un libro titulado «La conservación del corazón de las ciudades históricas». En cambio el plan «Voisin» de Le Corbusier de 1925, que afortunadamente no se llevó a la práctica, proponía arrasar el tejido de los viejos barrios de París, reemplazándolos por rascacielos en serie, y no conservar mas que algunos monumentos, como NotreDame, El Arco de Triunfo, el Sacré-Coeur y la torre Eiffel. Y esta teoría de hacer tabla rasa de los centros antiguos se extendió en Francia hasta que la frenó Malraux, siendo ministro de Cultura con la ley de sectores protegidos de 1962, y fue una plaga en muchas ciudades españolas - los años cuarenta a los sesenta - y aun subsiste en algunas ocasiones alentada por los intereses de los propietarios o por la posición de arquitectos que invocando el derecho de los artistas a la creación, no dudan en romper el carácter de los centros históricos.

Hoy como veremos la defensa de esos centros o esas ciudades históricas cuenta ya con una legislación muy abundante, y como tantas veces el acierto esta en coordinar el respeto a las creaciones antiguas con el desarrollo de la arquitectura moderna que tiene amplios espacios para su desarrollo.

\section{La normativa internacional sobre la defensa de los edificios y de los centros históricos de las ciudades}

Esta normativa, tan reciente que se remonta casi a la segunda mitad del siglo XX, tiene su origen básicamente en dos Instituciones: la UNESCO y el Consejo de Europa. Las normas de la primera tienen pretensión de alcance mundial y están abiertos sus proyectos y acuerdos a la ratificación de todos los países del mundo. En cambio las normas del Consejo de Europa se refieren a este continente y sus Convenios, Recomendaciones y Resoluciones tienen una extensión exclusivamente europea aunque han influido en la doctrina internacional por el valor de sus contenidos.

De los documentos de la UNESCO, el más importante es probablemente la Convención de 16-XI-1972, sobre la protección del Patrimonio mundial cultural y natural. Su objetivo es defender el Patrimonio Mundial de importancia histórica o artística, e ir haciendo una lista de los lugares que por sus valores excepcionales deben ser conservados para la humanidad entera y asegurar su protección mediante un reforzamiento de la cooperación entre las naciones. Al ratificar ese Convenio (lo que han hecho ya 155 Estados lo que demuestra la aceptación universal de sus principios) cada país signatario se com- 
promete a cuidar los sitios, conjuntos o monumentos declarados en su propio país por sus órganos competentes o por la misma UNESCO si los incluye en el Patrimonio de la Humanidad. En este caso sus bienes pueden disfrutar de las ayudas del Fondo del Patrimonio mundial, cuyos recursos pueden aplicarse para ayuda de esos bienes o conjuntos declarados, aunque en realidad esos fondos son escasos y van sólo a los países menos desarrollados.

En ese documento en su exposición de Motivos se dice entre otras cosas:

Constatando que el patrimonio cultural y el patrimonio natural están cada vez más amenazados de destrucción, no sólo por las causas tradicionales de deterioro sino también por la evolución de la vida social y económica que las agrava con fenómenos de alteración o de destrucción aún mas temibles,

Considerando que el deterioro o la desaparición de un bien del patrimonio cultural y natural constituye un empobrecimiento nefasto del patrimonio de todos los pueblos del mundo,

Considerando que la protección de ese patrimonio a escala nacional es en muchos casos incompleto, dada a la magnitud de los medios que requiere y la insuficiencia de los recursos económicos científicos y técnicos del país en cuyo territorio se encuentra el bien que ha de ser protegido,

Considerando que las convenciones, recomendaciones y resoluciones internacionales existentes en favor de los bienes culturales y naturales, demuestran la importancia que tiene para todos los pueblos del mundo, la conservación de esos bienes únicos e irremplazables de cualquiera que sea el país a que pertenezcan, Considerando que ciertos bienes del patrimonio cultural y natural presentan un interés excepcional que exige se conserven como elementos del patrimonio mundial de la humanidad entera, Considerando que, ante la amplitud y la gravedad de los nuevos peligros que les amenazan, incumbe a la colectividad internacional entera participar en la protección del patrimonio cultural y natural de valor universal excepcional prestando una asistencia colectiva que sin reemplazar la acción de Estado interesado la complete eficazmente. $\mathrm{Y}$ en su articulado se define en su artículo primero entre otras cosas como "patrimonio cultural»:

Los monumentos: obras arquitectónicas, de escultura o de pintura monumentales, elementos y grupos de elementos, que tengan un valor universal excepcional desde el punto de vista de la historia, del arte o de la ciencia.

Los conjuntos: grupos de construcciones, aisladas o reunidas, cuya arquitectura, unidad e integración en el paisaje les dé un valor universal 
excepcional desde el punto de vista de la historia, del arte o de la ciencia. $\mathrm{Y}$ en sus artículos 4,5 y 6 se dice:

Artículo 4

Cada uno de los Estados Partes en la presente Convención reconoce que la obligación de identificar, proteger, conservar, rehabilitar y transmitir a las generaciones futuras el patrimonio cultural y natural situado en su territorio, le incumbe primordialmente. Procurará actuar con ese objeto por su propio esfuerzo y hasta el máximo de los recursos de que disponga, y llegado el caso, mediante la asistencia y la cooperación internacionales de que se pueda beneficiar, sobre todo en los aspectos financiero, artístico, científico y técnico.

\section{Artículo 5}

Con objeto de garantizar una protección y una conservación eficaces y revalorizar lo más activamente posible el patrimonio cultural y natural situado en su territorio y en las condiciones adecuadas a cada país, cada uno de los Estados Partes en la presente Convención procurará dentro de lo posible:

d. adoptar las medidas jurídicas, científicas, técnicas, administrativas y financieras adecuadas, para identificar, proteger, conservar, revalorizar y rehabilitar ese patrimonio; y

\section{Artículo 6}

1. Respetando plenamente la soberanía de los Estados en cuyos territorios se encuentre el patrimonio cultural y natural a que se refieren los artículos 1 y 2 y sin perjuicio de los derechos reales previstos por la legislación nacional sobre ese patrimonio, los Estados Partes en la presente Convención reconocen que constituye un patrimonio universal en cuya protección la comunidad internacional entera tiene el deber de cooperar.

\section{Actuaciones del Consejo de Europa.}

Para los europeos es evidente que el Patrimonio Arquitectónico de los pueblos de Europa es extraordinariamente importante.

Europa ha sido la cuna de una de las culturas más decisivas para el desarrollo de la humanidad, y las creaciones de los diversos pueblos 
que se han ido asentando en estas tierras, han producido un conjunto de monumentos, ciudades, pueblos y edificios de todo tipo, de una enorme variedad y riqueza. Es imposible comprender la historia de la humanidad y el desarrollo de la arquitectura sin el testimonio de la arquitectura griega, romana, románica, gótica y renacentista, y luego de las aportaciones de los diversos pueblos europeos en la época moderna y contemporánea. El Patrimonio Arquitectónico Europeo es, por ello, sin minusvalorar los de otras culturas de otros continentes, indispensable para la comprensión de la historia de Europa y para el entendimiento de la evolución de la arquitectura y la habitación en el mundo.

Este Patrimonio Arquitectónico, como en general el Patrimonio Cultural de todos los pueblos, ha sufrido muchísimo a lo largo de los siglos, y aunque ha sido admirado en muchos momentos, ha tenido que soportar los embates del tiempo y de la incultura. Invasiones y guerras; ruinas de unos imperios sustituidos por otros poderes; reformas constantes en los edificios; emigraciones de las poblaciones; cambios de costumbres y cultos; expoliaciones de edificios, tumbas y monumentos; catástrofes naturales o causadas por el hombre; cambios de estilo y formas de vida; contaminación del ambiente; adelantos técnicos y desarrollo de las poblaciones, han ido afectándolo progresivamente. Todavía en este siglo hemos asistido a la degradación de ciudades enteras, bien por las dos grandes guerras del siglo XX con el poder de destrucción de las armas modernas, bien por la especulación y el desconocimiento del valor cultural de barrios, pueblos y ciudades antiguas. Se puede decir que, a pesar de ello, este siglo ha popularizado la importancia y valor, y la necesidad de conservación de los edificios históricos.

En el campo del patrimonio Cultural la importancia del Consejo de Europa y de sus trabajos creo que no ha sido en España nunca suficientemente reconocida. Y creo que no lo ha sido por una razón básica: por ser relativamente desconocida por la dificultad de acceder a ella. Por muchas razones: porque su trabajo se realiza durante un larguísimo periodo que empieza en 1949 y llega hasta nuestros días; porque el Consejo de Europa es una institución que ha desarrollado múltiples papeles en la creación de la idea de Europa pero siempre lejos del poder ejecutivo y no ha tenido el protagonismo o el eco de otros organismos europeos más políticos como han sido los Estados o luego la Comunidad Europea y la Unión Europea; porque ha funcionado tratando de introducir conceptos y conductos por la vía de la convicción y la reflexión y no por la de la imposición; o porque sus procedimientos de trabajo y de conocimiento o puesta en práctica de esos trabajos son múltiples ya que sus instrumentos jurídicos son tan diversos como: 
los Convenios que preparados en el Consejo son sin embargo Tratados que firman libremente los Estados miembros del Consejo de Europa que quieren adherirse a ellos; sus Recomendaciones son actos del Consejo de Europa que se dirigen a los Estados miembros pero que no tienen carácter obligatorio; y las Resoluciones de los ministros especializados son el resultado de conferencias, que no tienen efectos jurídicos inmediatos.

La esencia del Consejo de Europa que es una Institución de reflexión, encuentro, estudio y asesoramiento, con más poder de consejo que estrictamente político, hace que a veces no se le reconozca la gran labor que ha desempeñado en la unión de Europa, más allá de los límites de la Comunidad Europea.

Pero refiriéndome sólo al mundo del Patrimonio Cultural, me atrevo a afirmar que la Institución que más ha hecho por el Patrimonio Cultural europeo, por su reconocimiento primero, por su conservación luego, y finalmente por su valoración e importancia, ha sido sin duda en este medio siglo que ahora termina el Consejo de Europa. Pero es que además su papel ejemplar ha producido un efecto que excede, con mucho, de los límites de Europa.

Para todos los que hemos defendido la importancia del Patrimonio Histórico-Artístico como se decía antes, o Cultural, la actuación del Consejo de Europa en este campo ha sido absolutamente decisiva y ejemplar. Sus textos, realizados para Europa, contienen una doctrina que es aplicable al mundo entero, y de la que nos hemos alimentado cuantos en cualquier país del mundo hemos trabajado porque se reconociera el valor de ese Patrimonio, y se adoptaran las medidas para conservarlo, darlo a conocer, valorarlo y convertirlo en fuente de enriquecimiento espiritual y económico. Creo que toda la doctrina que ha surgido en este medio siglo en el mundo jurídico, cultural, administrativo, artístico y económico tiene una enorme deuda, o ha tenido un gran apoyo, en los textos surgidos del Consejo de Europa.

Aunque hay muchísimos documentos importantes del Consejo de Europa quiero destacar en este momento tres por la enorme trascendencia que han tenido y lo que han significado de consagración de la importancia que tiene el Patrimonio Cultural:

- El Convenio Cultural Europeo de 19 de diciembre de 1954.

- La Carta Europea del Patrimonio Arquitectónico de 26 de septiembre de 1975 y su consecuencia que es la Declaración, de Amsterdam de octubre de 1975.

- El Convenio para la salvaguarda del Patrimonio Arquitectónico de Europa firmado en Granada el 3 de octubre de 1985. 
El Convenio de 1954 tiene el valor por su fecha, de su valor precursor, de fijarse cuando Europa estaba todavía saliendo de las consecuencias de la guerra y sus problemas eran muchos, su riqueza todavía escasa, su economía relativamente modesta, como objetivos que:

Cada Estado tome las medidas apropiadas para salvaguardar su aportación al patrimonio cultural común de Europa (hablando de ello dos años antes del Tratado de Roma que es el origen de la Unión Europea); anime a sus ciudadanos «al estudio de las lenguas, la historia y la civilización de las otras Partes contratantes», y logre que «las Partes contratantes se consulten, dentro del marco del Consejo de Europa, a fin de concertar su acción en orden al desarrollo de actividades culturales de interés europeo».

Los Convenios más importantes surgidos sobre la defensa y protección del Patrimonio Arquitectónico europeo que comprende Monumentos y Conjuntos, y dentro de estos los centros históricos de pueblos y ciudades han sido aparte de los citados más arriba:

El primer Convenio Europeo para la Protección del Patrimonio Arqueológico (Londres 1969).

El Convenio Europeo sobre infracciones cometidas contra los bienes culturales (Convenión de Delfos 1985).

El Convenio Europeo para la Protección del Patrimonio Arqueológico (Convención de Malta 1992).

Aparte de ello hay una serie de Recomendaciones entre las cuales son especialmente significativas a los efectos de nuestro estudio:

La de 1989 sobre la Protección y Puesta en valor del Patrimonio Arquitectónico Rural.

La de 1991 sobre medidas apropiadas para promover la financiación de la Conservación del Patrimonio Arquitectónico.

La de Conservación de los Sitios Culturales integrada en las Políticas del Paisaje (1995).

Y las resoluciones de la Cuarta Conferencia Europea de Ministros responsables del Patrimonio Cultural de Helsinkí 1996, en especial la Declaración de Helsinki sobre la Dimensión política de la Conservación del Patrimonio Cultural en Europa.

Como es imposible hacer un resumen de toda esta legislación en un trabajo como el presente, voy a hacerlo solo de dos de estos documentos, la Declaración de Amsterdam de 1975 porque sienta las bases de la conservación de monumentos, ciudades, centros históricos y conjuntos y el Convenio de Granada por su carácter normativo.

En 1975 el Comité de Ministros del Consejo de Europa aprueba la Carta Europea del Patrimonio Arquitectónico, que se proclama so- 
lemnemente en el Congreso sobre el Patrimonio Arquitectónico Europeo que tuvo lugar en Amsterdam en octubre de 1975, y se aprueba la llamada Declaración de Amsterdam. Estos dos documentos sientan las bases de toda la política de defensa y conservación del Patrimonio Arquitectónico Europeo y contienen una serie de afirmaciones enormemente nuevas en ese momento y que van a ser el origen de un cambio en las conductas y legislaciones de la mayoría de los países europeos, y la fuente y justificación de una serie de trabajos que, hasta hoy, va a desarrollar o promover el Consejo de Europa.

La Carta Europea del Patrimonio Arquitectónico afirma, entre otras muchas cosas, lo siguiente:

«Reconociendo que el Patrimonio Arquitectónico, expresión irreemplazable de la riqueza y de la diversidad de la cultura europea, es patrimonio común de todos los pueblos y que su conservación exige en consecuencia la solidaridad efectiva de los Estados europeos;

Considerando que la conservación del PA depende ampliamente de su integración en el marco de vida de los ciudadanos y de su respeto por los planes de ordenación del territorio y del urbanismo...

Reafirma su voluntad de promover una política europea común y una acción concertada de protección del PA apoyándose en los principios de su conservación integral...

Adopta y proclama los principios de la presente Carta:

1. El Patrimonio Arquitectónico Europeo está formado, no sólo por nuestros monumentos más importantes, sino también por los conjuntos que constituyen nuestras sociedades antiguas y nuestros pueblos con su entorno natural o construido. El PA testimonia la presencia de la Historia y su importancia en nuestra vida.

2. La encarnación del pasado en el PA constituye un entorno indispensable para el equilibrio y el desarrollo del hombre. Es una parte esencial de la memoria de los hombres de hoy y si se dejara de transmitir a las generaciones futuras con su riqueza auténtica y su diversidad, la humanidad sería amputada de una parte de la conciencia de su propia historia.

3. El PA es un capital espiritual, cultural, económico y social de valores irreemplazables. Además, la necesidad de ahorrar recursos se impone a nuestra sociedad. Lejos de ser un lujo para la colectividad la utilización de ese Patrimonio, es una fuente de economía. 
4. La estructura de los conjuntos históricos favorece el equilibrio armonioso de las sociedades. Estos conjuntos constituyen, en efecto, medios adecuados al desarrollo de un largo abanico de actividades.

5. El PA tiene un valor educativo determinante. La imagen y el contacto directo con él tienen una importancia decisiva en la formación de las personas.

6. Este Patrimonio está en peligro. Está amenazado por la ignorancia, por la vejez, por la degradación en todas sus formas, y por el abandono. Cierto urbanismo es destructor cuando las autoridades son exageradamente sensibles a las presiones económicas y a las exigencias de la circulación. La tecnología contemporánea mal aplicada destruye las estructuras antiguas.

7. La conservación integral es el resultado coordinado de técnicas de restauración y de la búsqueda de funciones apropiadas. La evolución histórica ha llevado a los centros degradados de las ciudades, y en ocasiones a los pueblos abandonados, a convertirse en reservas de viviendas baratas. Su restauración debe ser llevada a cabo con espíritu de justicia social y no debe significar el éxodo de todos los habitantes de condición modesta.

8. La conservación integral exige la puesta en funcionamiento de medidas jurídicas, administrativas, financieras y técnicas.

Medidas jurídicas. Deben utilizarse todas las leyes y reglamentos existentes que puedan concurrir a la salvaguardia y a la protección del Patrimonio.

Medidas financieras. El mantenimiento y la restauración del PA debe gozar de todas las ayudas e incitaciones financieras necesarias comprendidas las medidas fiscales. Éstas deben ser, al menos, iguales a las que se conceden a la construcción nueva.

Medidas técnicas. Los arquitectos, los técnicos o empresas especializadas y los artesanos calificados para la restauración, son insuficientes. Es preciso desarrollar estas medidas y favorecer el desarrollo del artesanado, amenazado de desaparición.

9. La ayuda de todos es indispensable para el éxito de la conservación integral. Cada generación no dispone de ese Patrimonio más que a título vitalicio. Es responsable de su transmisión a las generaciones futuras.

10. El PA es un bien común de nuestro continente. Todos los problemas de conservación son comunes a toda Europa y deben ser tratados de forma coordinada. Compete al Consejo de Europa asegurar la coherencia de la política de sus Estados miembros y promover su solidaridad.» 
Y la Declaración de Amsterdarn, en la que se puede afirmar que está en germen todo lo que después se ha ido haciendo o recomendando en defensa del PAE, dice en su Prefacio, firmado por el secretario general del Consejo de Europa, cosas como estas:

«La Declaración de Amsterdam cristaliza un momento importante de la evolución del pensamiento europeo en el campo de la conservación del PA. Llama la atención en esta evolución la ampliación de ese concepto.

Limitada originalmente al Monumento, Sitio o Conjunto de interés relevante, la noción de Patrimonio Arquitectónico cubre hoy todos los conjuntos edificados que aparecen como una entidad, no solamente por la coherencia de su estilo, sino también por la impronta de la historia de grupos humanos que han vivido en ellos durante generaciones.

Es muy importante que los gobiernos tomen nota de las enseñanzas de este Congreso y afecten a la conservación del Patrimonio medios proporcionados a la amplitud de esta tarea. Tal opción política y económica implica, naturalmente, el apoyo de la opinión pública.

La realización de la conservación integral necesita, por consecuencia, dos condiciones previas: una opinión pública consciente y vigilante y medios presupuestarios adecuados».

Y en la propia Declaración, se contienen textos como los siguientes:

«El Congreso pone el acento sobre las consideraciones esenciales siguientes:

Además de su inestimable valor cultural, el Patrimonio Arquitectónico de Europa lleva a todos los europeos a tomar conciencia de una comunidad de historia y de destino. Su conservación reviste, por ello, una importancia vital...

La conservación del PA debe ser considerada, no como un problema material, sino como objetivo preferente de la planificación urbana y de la ordenación del territorio...

La conservación integral compromete la responsabilidad de los poderes locales y exige la participación de los ciudadanos...

Los poderes locales deben atribuir a los edificios funciones que, respetando su carácter, respondan a las condiciones de vida actuales y garanticen así su sobrevivencia; y favorecer la formación y funcionamiento eficaz de asociaciones sin ánimo de lucro de restauración y rehabilitación... 
La toma en consideración de los factores sociales condiciona el éxito de toda política de conservación integral. Una política de conservación implica también la integración del PA en la vida social...

La conservación integral exige una adaptación de las medidas legislativas y administrativas. Habiéndose ensanchado la noción de Patrimonio Arquitectónico, la condición previa de una acción eficaz es una reforma profunda de la legislación. El legislador debe tomar las disposiciones necesarias para redistribuir de manera equilibrada los créditos presupuestarios reservados a la ordenación urbana y afectados respectivamente a la rehabilitación y a la construcción; conceder a los ciudadanos que decidan rehabilitar un edificio antiguo, ventajas financieras equivalentes, al menos, a las que gozaría una construcción nueva; y revisar, en función de la nueva política de conservación, el régimen de ayudas financieras del Estado y de los demás poderes públicos...

La conservación integral exige medios financieros apropiados. Se puede afirmar con seguridad que no existe apenas país en Europa donde los medios Financieros afectados a la conservación sean suficientes. Las ventajas financieras y fiscales actualmente existentes para la construcción nueva, deben ser concedidas en las mismas proporciones para el mantenimiento y conservación de los edificios antiguos. Es capital estimular a las fuentes de financiación privada, principalmente de origen industrial. Numerosas iniciativas privadas han demostrado el papel positivo que puedan jugar conjuntamente con los poderes públicos, tanto a nivel nacional como local.

\section{Convenio de Granada de 1985}

Todos los trabajos realizados desde 1975 son los que hicieron posible la trascendental reunión de los ministros de Cultura de los países miembros del Consejo de Europa, que tuvo lugar en España, en una de las ciudades que, no sólo es una parte importante del Patrimonio Histórico Español, sino que es un ejemplo fundamental del Patrimonio Cultural de la Humanidad: Granada.

El documento, que se aprobó el 3 de octubre de 1985 en la citada ciudad, firmado por dieciséis ministros de Cultura, es una pieza básica que resume de forma notable los principios en que se debe inspirar la protección del PAE, y ha sido el pilar en el que se han apoyado las siguientes actuaciones del Consejo de Europa.

El artículo 2 dice que «cada Estado parte se compromete a identificar con precisión los monumentos, conjuntos y sitios protegibles, y a practicar un Inventario de ellos». En el artículo 3, cada Estado parte se 
compromete a poner en práctica un régimen legal de protección del PA y a asegurar en el marco de ese régimen y según las modalidades propias de cada Estado o región, la protección de los monumentos, los conjuntos y los sitios; y en el artículo 4, cada parte se compromete a evitar que los bienes protegidos sean desfigurados, degradados o demolidos. En ese sentido se compromete cada parte, si no lo está ya, a introducir en su legislación disposiciones que prevean:

a) La sumisión a una autoridad competente de los proyectos de demolición o modificación de monumentos;

b) La sumisión a la autoridad competente de los proyectos que se refieran, en todo o en parte, a un conjunto arquitectónico o a un sitio y que afecten a la demolición, a la construcción de nuevos edificios o a modificaciones importantes que atentarían al carácter de ese conjunto o sitio;

c) La posibilidad de que los poderes públicos obliguen al propietario a efectuar obras o a realizarlas en su lugar; y

d) La posibilidad de expropiar un bien protegido.

Los artículos 6 y 14 establecen medidas complementarias para hacer más fácil esa conservación. Por el artículo 6, cada Estado parte se compromete a prever, dentro del límite de sus presupuestos, un apoyo financiero de los poderes públicos a las obras de mantenimiento y restauración del PA sito en su territorio. Y en el artículo 14, a crear estructuras de información, consulta y colaboración entre el Estado, las colectividades locales, las instituciones y asociaciones culturales, y el público; y a favorecer el desarrollo del mecenazgo y de las asociaciones sin fin lucrativo que se dediquen a este campo.

\section{La normativa española sobre la defensa de los edificios y de los centros historicos de las ciudades}

Dentro del Patrimonio Cultural, el Patrimonio Arquitectónico ha ocupado siempre un lugar especial. Se puede decir que las primeras disposiciones protectoras del Patrimonio Cultural en nuestras leyes, van casi siempre referidas a los inmuebles. Aunque con ocasión de la creación por Fernando VI de la Real Academia de Bellas Artes de San Fernando se incluye la preocupación por las «obras de pintura, escultura y arquitectura», se atiende especialmente en muchas de sus manifestaciones a la conservación de los monumentos y a controlar la capacidad "para medir, tasar o dirigir obras de modo que no se autorizara a realizar esas competencias a persona alguna sin que preceda el examen y aprobación que le dé la Academia de ser hábil y a propósito para estos ministerios». 
Una Real Cédula de 6 de junio de 1803, encomendaba también a la Academia de la Historia «recoger y conservar los monumentos antiguos que se descubran en el Reino, con objeto de impedir su destrucción». En 1844 una Real Orden crea las Comisiones de Monumentos Históricos y Artísticos, una en cada provincia y otra central. En 1850 dos Reales Ordenes, de 1 de septiembre y 10 de octubre, tratan de proteger los edificios del Estado cedidos a corporaciones y particulares. Se respeta en ellas la propiedad privada en cuanto a las obras interiores en inmuebles particulares, ya que «éstos tienen derecho a ejecutar cuanto les parezca conveniente en sus respectivas propiedades». pero se limita esa libertad en cuanto a las fachadas, capillas y demás parajes abiertos al público». En 1851 otra Real Orden exige que la Real Academia de San Fernando autorice la instalación de estatuas, efigies y bajorrelieves en edificios. monumentos públicos e interior de iglesias y capillas abiertas al público. Y en un Decreto de 16 de diciembre de 1873 se ordena a ayuntamientos y diputaciones que vigilen los monumentos a efectos de evitar la destrucción de edificios públicos con méritos artísticos e históricos.

Con estos precedentes no es extraño que nuestras primeras leyes del siglo XX se refieran sobre todo a los monumentos y a la conservación de ruinas y antigüedades. Este sentido tienen el Real Decreto de 1 de junio de 1900 que ordena la formación del Catálogo Monumental y Artístico, la Ley de 7 de julio de 1911 sobre la excavaciones y las ruinas de edificios, y la Ley de Monumentos de 1915.

Tras estas disposiciones se publica una norma muy importante que es el origen de la moderna legislación española y a la que no se suele reconocer su trascendencia como protectora del Patrimonio y que influirá en la mucho más famosa Ley de 1933, el Decreto-ley de 9 de agosto de 1926, sobre protección y conservación de la riqueza artística, en la que, por primera vez, se delimita el Tesoro artístico nacional y se pone todo él bajo la tutela y protección del Estado.

Esta Ley dedica tanto en la Exposición de Motivos como en el texto, una mayor atención a los monumentos e inmuebles.

Este criterio es el que también siguen las legislaciones europeas. Aún hoy hay países en que su regulación legal versa casi exclusivamente sobre los bienes inmuebles, dejando los bienes muebles a la autonomía de la voluntad de los particulares. Y por ejemplo en Francia todas las primeras leyes se refieren al Patrimonio Arquitectónico, como la Ley de 31 de diciembre de 1913 que se refiere a los monumentos históricos, o la Ley de 2 de mayo de 1930, relativa a la protección de conjuntos naturales y de emplazamientos de carácter histórico, científico, legen- 
dario o pintoresco, o la Ley de 27 de septiembre de 1941 sobre excavaciones arqueológicas, y hay que esperar a ese año 1941 para encontrar la primera ley sobre las obras de arte muebles.

Eduardo García de Enterría, hablando de «Una nueva legislación del Patrimonio Artístico», en un estudio publicado en Madrid en 1984 por Hispania Nostra, señala tres razones básicas para el deterioro del PHA en el siglo XIX, que son: la seguridad en sí mismo del nuevo siglo y el abandono de las precauciones que el siglo XVIII empezó a tejer para defender ese Patrimonio; la potenciación de la institución de la propiedad privada como central en la sociedad y sagrada e inviolable según los textos de la Revolución Francesa; y el utilitarismo de la nueva clase industrial que predica el triunfo de las tendencias más activas frente a los valores inermes, como son los valores artísticos e históricos.

Ello explica, a juicio de Enterría, que en el siglo XIX se produzca una primera degradación del Patrimonio arquitectónico. «Ello explica, que en el siglo XIX se produzca esa pavorosa degradación del Patrimonio artístico, que inicia la Guerra de la Independencia (guerra que alimentó de nuestros tesoros a unos y otros ejércitos extranjeros, como es fácil y doloroso ver en los principales museos del mundo), que continúa con la desamortización, gigantesca destrucción artística; que sigue con la desmilitarización de las ciudades (éstas estaban amuralladas y estaban sometidas, desde el punto de vista administrativo, al ramo de guerra; la desmilitarización ocurre a mitad del siglo XIX, todavía las murallas han jugado un papel en la Guerra de la Independencia y en la primera guerra carlista; se destruyen sistemáticamente las murallas para dar paso a la primera gran revolución urbana de la modernidad ) y que se consuma con las técnicas de esta revolución urbana, el ensanche, por un parte, con su cuadriculado, con su estructura de ajedrez para los nuevos barrios puramente utilitarios, sin ninguna sensibilidad hacia otros valores; y, en fin, la segunda gran técnica urbanística del siglo XIX, la llamada, reforma interior, que es precisamente la ruptura de la trama urbana consolidada, de los viejos barrios, para introducir en ellos los bulevares o grandes vías impuestos por la nueva preceptiva higiénica y el ulterior desarrollo de los medios de comunicación. Todo ello, conjugadamente, va a ocasionar una destrucción extraordinaria de nuestro Patrimonio histórico-artístico, arquitectónico.

Siguiendo con una referencia a la legislación española sobre esta materia en el periodo de la República, hemos de citar como normas importantes:

La Constitución de 1931 declaró en 'su artículo 45: «Toda la riqueza artística e histórica del país, sea quien fuere su dueño, constituye 
tesoro cultural de la Nación y estará bajo la salvaguardia del Estado, que podrá prohibir su exportación y enajenación y decretar las expropiaciones legales que estimare oportunas para su defensa. El Estado organizará un registro de la riqueza artística e histórica, asegurará su celosa custodia y atenderá a su perfecta conservación. El Estado protegerá también los lugares notables por su belleza natural o por su reconocido valor artístico o histórico».

Y antes también de la Ley de 1933 se dictó la Ley de 10 de diciembre de 1931, en la que se establece la norma más limitativa respecto a la disposición de bienes culturales de nuestra historia. En ella se prohíbe a todas las personas físicas y jurídicas enajenar bienes inmuebles ni objetos artísticos, arqueológicos o históricos que tengan más de cien años de antigüedad, sin previo permiso del Ministerio de que dependan y mediante escritura pública.

En el período republicano se dicta, por fin, la que va a ser la ley más duradera -más de cincuenta años de vigencia-, y más significativa para la defensa del Patrimonio Histórico y Artístico, la Ley de 13 de mayo de 1933, que se completa con su Reglamento de 16 de abril de 1936. Esta parecía una ley que debía resolver los problemas de nuestro Patrimonio, pero la realidad no fue esa. No se llegó a hacer un inventario, ni se logró su aplicación eficaz, ni las circunstancias fueron las más propicias para la expansión de los acertados principios que la inspiraron.

A raíz de la guerra civil del 36-39 se publicaron bastantes normas sobre esta materia, de las que las más importantes fueron las siguientes:

- Decretos de 9 de marzo de 1940 y 19 de abril de 1941, en los que se ordena la realización del Catálogo Monumental de España.

- Decreto de 22 de abril de 1949, de protección de todos los castillos españoles.

- Decreto de 12 de junio de 1953, que es muy importante porque regula la transmisión de antigüedades y obras de arte dentro y fuera del territorio nacional, estableciendo las normas para el ejercicio del derecho de tanteo y retracto por el Estado.

- El Decreto de 14 de marzo de 1963 extiende la protección del Patrimonio Histórico Artístico a todos los escudos, emblemas, piedras heráldicas, rollos de justicia, cruces de término y piezas similares de interés histórico-artístico.

- En 1973 un Decreto de 22 de febrero- coloca bajo la protección del Estado los «hórreos o «cabazos» antiguos existentes en Asturias y Galicia, extendiendo así la protección a bienes etnográficos. 
- Y en 1977, tras las primeras elecciones democráticas, con el Gobierno que surge de ellas, se crea por primera vez el Ministerio de Cultura, cuya estructura orgánica y funciones se establecen en el Decreto de 27 de agosto de 1977.

Con ello llegamos a un nuevo periodo que comienza con la Constitución de 1978 y sigue con la ley de 1985 y su Reglamento actualmente vigentes, pero que hay que coordinar con toda la legislación de las Comunidades Autónomas, que es al día de hoy ya muy abundante y sigue creciendo. Hay leyes en Cataluña, País Vasco, Galicia, Canarias, Andalucía, Valencia, Aragón, Castilla-La Mancha y Madrid.

En este momento y antes de entrar, aunque ha de ser necesariamente de forma esquemática, en el análisis de esa legislación, convendría pararnos en dos temas previos.

¿Cuál ha sido la evolución y situación de nuestro Patrimonio Arquitectónico y de nuestras ciudades y sus centros históricos desde que aparece la preocupación por su conservación? y

¿Cuál es el tipo de política y legislación conveniente para mantener nuestras ciudades, pueblos y conjuntos históricos?

En cuanto a lo primero hay que reconocer que la degradación de nuestro Patrimonio Arquitectónico es reciente, porque la verdad es que aunque, maltratado, olvidado y minusvalorado, la mayor parte de él se conservaba bastante bien hasta principios del siglo XIX.

Probablemente más por la incapacidad de destruirlo, por el estancamiento de nuestra economía, y por la propia tendencia de los edificios a mantenerse en pie, que por una política protectora y restauradora. Hasta esa época, los daños eran debidos más a acontecimientos naturales o degradación por falta de cuidados o de uso, incendios, que a la obra del hombre. No faltaban reformas estilísticas desafortunadas, expolios de restos o ciudades abandonadas, como Medina Azahara, utilización de viejos conjuntos o monumentos como cantera para nuevas construcciones, o las típicas sustituciones de templos de distintas religiones en sus épocas de esplendor (templos cristianos sobre otros paganos, mezquitas sobre templos visigóticos, y de nuevo iglesias sobre mezquitas), de cuyo fenómeno es paradigma la construcción de la catedral dentro de la mezquita de Córdoba.

Las grandes catástrofes del Patrimonio Arquitectónico Español se pueden resumir en una serie de acontecimientos de los siglos XIX y $\mathrm{XX}$, considerados, curiosa paradoja, en su época, como manifestaciones de progreso. Aunque ha de ser muy breve mente no nos resistirnos a enumerarlos, por orden cronológico: 
- La destrucción y almoneda de cientos de edificios artísticos o históricos, muchas veces con su contenido de muebles y bibliotecas, transmitidos a particulares como consecuencia de la política desamortizadora. sin ninguna obligación de conservarlos, o abandonados al ser expulsadas las instituciones religiosas que eran sus propietarias y ocupantes.

- La destrucción de casi todas las murallas de nuestras antiguas ciudades como reflejo de un espíritu "moderno» que creía que, para hacer el ensanche de las poblaciones, era preciso derribar los viejos bastiones. Estas dos últimas medidas han sido probablemente las que más perjuicio han causado en un corto espacio de tiempo a nuestro Patrimonio inmobiliario, artístico e histórico.

- La reforma interior de las ciudades en el siglo XIX y en siglo $\mathrm{XX}$, que supone la ruptura de la trama urbana consolidada, de los viejos barrios, para abrir en ellos las «gran vías» impuestas por la nueva preceptiva higiénica y el ulterior desarrollo de los medios de comunicación. En vez de respetar y sanear las viejas ciudades y expansionarse sin destruir los viejos centros, se cayó en el error, en España en mayor grado que en Inglaterra, Francia o Alemania, que no estuvieron tampoco libres de él, de creer en la virtud de lo moderno como cúmulo de perfecciones y en desconocer la belleza, utilidad y razón de ser de las viejas aglomeraciones urbanas.

- Y, finalmente, la gran migración del campo a la ciudad de las décadas de 1940 y 1950, que se prolonga y llega aún a nosotros. Este movimiento de población que transformó a España de rural en urbana, y que tuvo unos beneficiosos efectos en nuestra economía, y en la modernización de nuestro país, se realizó desde un punto de vista arquitectónico y cultural con una enorme insensibilidad y falta de respeto para nuestro Patrimonio Arquitectónico. Ese «desarrollo» supuso la degradación de barrios y edificios de ciudades tan importantes como Valladolid, Sevilla, Valencia, Granada, Zaragoza y otras muchas, o la destrucción casi de calles enteras como la Castellana de Madrid. En todas ellas han quedado muestras espléndidas de lo que eran, pero las pérdidas son casi incontables. Y si eso sucedió en las ciudades, muchísimos pueblos, unos por ser abandonados y otros por ser «modernizados», sufrieron un deterioro enorme. Las normas, que existían, de las leyes generales, se vieron impotentes ante la incultura y la especulación. Se han destruido en esta segunda mitad de siglo, y es tristísimo reconocerlo, y se siguen destru- 
yendo de vez en cuando, miles de magníficos ejemplos de la arquitectura popular, sustituyéndolos por horribles edificios altos, sin estilo ninguno, pensados sólo para obtener el mayor beneficio, ajenos al entorno, molestos de ver hoy e irrespetuosos con el ayer y el mañana. Este urbanismo desdichado no ha respetado edificios antiguos, parajes o paisajes o perfiles de pueblos y ciudades, calles y barrios con personalidad; ni el interior de las ciudades ni su entorno o paisaje, ni las costas y playas, ni siquiera las ciudades más señeras o declaradas Patrimonio de la Humanidad, se han librado. Y el ataque continúa. Las edificaciones que se pretenden hacer junto al acueducto de Segovia, o la edificación al lado del castillo de San Servando, en Toledo, o los atentados a las imágenes clásicas, Patrimonio Cultural sin duda, de Salamanca o Segovia, nos dicen que no es posible creer que el peligro ha pasado.

$\mathrm{Y}$ en cuanto a lo segundo es evidente que aparte de la exigencia del cumplimiento de las leyes protectoras es preciso una actividad de fomento de la conservación que exige, como ha puesto de relieve el Consejo de Europa en un documento titulado «'Problemática de la financiación de la conservación del Patrimonio Arquitectónico Europeo», una serie de medidas:

a) Jurídicas y administrativas, que creen un ambiente favorable al lanzamiento de proyectos de conservación como: adopción de una estrategia urbanística y de planificación que concilie las exigencias culturales de la conservación con la rentabilidad de las operaciones; la simplificación de los procesos administrativos; y nuevos procedimientos jurídicos para facilitar y promocionar las inversiones en conservación y restauración inmobiliaria.

b) Financieras, consistentes en subvenciones y tratamiento fiscal favorable adaptado a la naturaleza y necesidades de los bienes protegidos y

c) de promoción del mecenazgo y el patrocinio aplicados a las ciudades, pueblos y conjuntos históricos.

Las autoridades españolas, los poderes públicos, deben garantizar la conservación de los bienes que integran ese Patrimonio, cualquiera que sea su régimen jurídico y titularidad (art. $46 \mathrm{CE}$ ). El problema es que muchas veces se plantean problemas de competencias. Los municipios, que tienen reconocida su autonomía en el artículo 140 de la $\mathrm{CE}$, son normalmente los encargados de conceder las licencias de construcción y derribo, pero olvidan las normas preceptivas de la Ley de 
1985 y aunque hay municipios muy conscientes de la importancia del Patrimonio Arquitectónico, hay muchos casos de ayuntamientos que, por incultura, por intereses particulares o por un mal entendido desarrollo del lugar, aprueban construcciones que dañan al entorno, al paisaje $\mathrm{o}$, incluso, a los monumentos declarados; es menos frecuente que autoricen derribos de edificios que formen parte del $\mathrm{PHE}$, pero las autorizaciones para construir donde o como no se debe, son aún muy frecuentes. $Y$ una vez producidos estos hechos no son fáciles de volver atrás. Evidentemente, las comunidades autónomas suelen tener competencia sobre ordenación del territorio y urbanismo (art. 148, 1,3 $3^{\text {a }}$ CE) y sobre Patrimonio monumental (art. 148, 1, 16. ${ }^{a}$ ), pero tampoco es una garantía absoluta porque, mientras hay algunas muy cuidadosas, otras asisten impertérritas a deterioros de pueblos enteros de indudable valor histórico o artístico por su arquitectura popular, aunque no tengan obras maestras o declaradas de interés cultural. Y de todo ello se pueden presentar ejemplos recentísimos.

No cabe duda que la única fórmula es la coordinación de las comunidades autónomas y de la Administración central a través de la norma especial del artículo 149, 2 de la CE que dice: "Sin perjuicio de las competencias que podrán asumir las comunidades autónomas, el Estado considerará el servicio de la cultura como deber y atribución esencial y facilitará la comunicación cultural entre las comunidades autónomas, de acuerdo con ellas.»

Esta labor conjunta es la única, sobre la base de denuncias de la ciudadanía, o de vigilancia de las autoridades, que puede evitar los muchos daños que se siguen produciendo al Patrimonio Arquitectónico por abusos, ignorancia o incapacidad de los poderes municipales en muchos lugares de España.

Asimismo es preciso cambiar la política de conservación del $\mathrm{Pa}$ trimonio inmobiliario, tanto desde el punto de vista sustantivo como fiscal. Es absurdo, por ejemplo, que nuestra legislación de rehabilitación (Real Decreto 2329/1983) establezca una serie de beneficios para la rehabilitación de edificios destinados a vivienda y no los extienda a la restauración, casi siempre más difícil y costosa, de edificios históricos que no tengan esa aplicación; o que sigan teniendo un régimen fiscal y de ayuda más favorable la edificación de nueva planta que las obras de conservación. Es preciso cuanto antes que nuestra legislación siga las recomendaciones y criterios marcados por el Consejo de Europa y adapte la legislación a esas ideas.

4. En resumen, podríamos decir que para conservar nuestro Patrimonio Arquitectónico habría que conseguir dos cosas: 


\section{La protección jurídica de las ciudades históricas}

- Convencer a los españoles de las ventajas culturales económicas y de calidad de vida que tiene que contar con un gran Patrimonio Histórico y conservarlo. Ello exige dedicar especial atención a la educación y la promoción. La primera tarea, sin duda, es la de enseñar la importancia del Patrimonio Arquitectónico: lo que influye en la calidad de vida habitar un ambiente propio; el valor social y cultural de las ciudades y monumentos antiguos; lo que contribuyen al desarrollo económico, turístico y ambiental; el placer que proporciona la contemplación de la belleza y el placer que proporcionan a la comunidad los bienes culturales, que además pueden ser disfrutados por muchas personas y generaciones sucesivamente. Y enseñar, además, que conservar esos edificios y conjuntos no es un lujo, sino que, en el mundo actual, conservar una ciudad bella y respetarla, tener barrios y paisajes visitables, tener en ellos una vida artística y cultural, es una fuente de beneficio económico directo e indirecto para ese pueblo, región o país. Sin una conciencia en la sociedad de la importancia del Patrimonio Arquitectónico, es muy difícil preservar éste.

- Además de convencer, hay que incentivar las inversiones en conservación de esos bienes y en su rehabilitación y uso. Esto afecta ya a la normativa. Sin perjuicio de la defensa coactiva para conservar esos edificios, lo que hay que tener son unas normas que hagan que la política marcada por el Estado, se siga, no por temor a la sanción, sino por convicción o conveniencia. Porque si es mejor negocio conservar y rehabilitar que derribar, la gente querrá mantenerlos. Y si es al revés, por muchas prohibiciones que se establezcan, ese Patrimonio correrá un grave peligro.

Para conservar esos bienes, lo primero es que no constituyan una carga para su titular, y dado que normalmente los gastos de conservación son altos y la utilidad directa de algunos de ellos no es clara, deben dárseles un tratamiento fiscal adecuado a su doble interés, público y privado, y a sus posibilidades de utilización y rentabilidad.

$\mathrm{Si}$ se hace una política que haga que todos los ciudadanos aprecien y sientan como suyos esos bienes, en cuanto embellecen su entorno; que sus propietarios o poseedores no los vean como una carga, comparado con un solar o un edificio moderno, y que puedan adaptarlos a las necesidades y comodidades que la vida actual exige, estaremos en el mejor camino para que, sin grave coste para los poderes públicos, conservemos ese Patrimonio Arquitectónico excepcional y extensísimo que tiene España. 
Llegados a este punto, nos corresponde hacer un breve examen de nuestra legislación vigente, distinguiendo entre nuestra Constitución, nuestra legislación estatal y la normativa autonómica,

Nuestra Constitución en su artículo 46 dice:

ARTÍCUL0 46. $=$ Los poderes públicos garantizarán la conservación y promoverán el enriquecimiento del patrimonio histórico, cultural y artístico de los pueblos de España y de los bienes que lo integran, cualquiera que sea su régimen jurídico y su titularidad. La Ley penal sancionará los atentados contra este patrimonio".

A los efectos de este trabajo nos basta con recordar los siguientes aspectos y consecuencias de la norma:

1. Que lo primero que dice es que los poderes públicos garantizarán la conservación del patrimonio histórico, cultural y artístico de los pueblos de España. Lo primero como es lógico, es garantizar la conservación ya que además de ser el primer riesgo, difícilmente se puede promocionar, enriquecer o usar ese Patrimonio si no se preserva, como primera medida, lo que tenemos.

2. Que se refiere a todos los bienes cualquiera que sea su régimen jurídico y su titularidad. O lo que es lo mismo que es igual que los bienes sean del Estado, o de otras personas privadas o públicas incluidas en este último las de los Ayuntamientos, de personas jurídicas públicas extranjeras y naturalmente los de la Iglesia que es uno de los titulares de mayor parte del Patrimonio Arquitectónico español .

3. Que el incumplimiento de las normas que supongan atentados contra este Patrimonio lleva aparejados las sanciones que establezcan las leyes que desarrollen esta norma.

Pero aparte de este articulo 46 hay varios otros preceptos constitucionales que complementan lo que aquel dice. Son especialmente importantes.

El art. 10.2 que dice que «las normas relativas a los derechos y deberes fundamentales (en cuyo Capítulo III está el art. 46) se interpretarán de conformidad con los tratados y acuerdos internacionales sobre las mismas materias». Y por lo tanto los acuerdos multinacionales como los convenios de la UNESCO ratificados por España o los convenios y resoluciones de la Comunidad Europea o del Consejo de Europa no podrán ser olvidados a la hora de interpretar el artículo 46 y las normas que lo desarrollan.

El art. 149.2, ya citado antes, que dice que «Sin perjuicio de las competencias que podrán asumir las Comunidades Autónomas, el Estado 
considerará el servicio de la cultura como deber y atribución esencial". Este es un párrafo especial para la Cultura sin ningún otro paralelo en la Constitución para otras materias también importantes. Excepción sólo justificada e inteligible por la importancia que la Constitución da a esta materia.

La legislación estatal se contiene básicamente en la ley del PHE de 1985 y su reglamento de 1986. Las normas más importantes para los Conjuntos Históricos o los Pueblos y sitios Históricos, dentro de los cuales hay que comprender los barrios o centros de las Ciudades, son los artículos: 20 que establece que la declaración de un Conjunto o Sitio Histórico, como Bien de Interés Cultural determina la obligación de redactar un Plan Especial de Protección del Area afectada que exige el informe favorable de la Administración competente para la protección de los bienes culturales afectados. En ese Plan se deben prever los usos permitidos, las áreas de rehabilitación, los criterios de conservación, y no se permitirán alineaciones nuevas ni licencias contrarias al Plan aprobado, pudiendo la Administración competente adecuar la reconstrucción o demolición con cargo al Organismo que hubiere dado una licencia indebidamente.

$\mathrm{El}$ artículo 21 que ordena que en los Conjuntos Históricos se realice la catalogación de todos los elementos unitarios que forman el Conjunto, tanto inmuebles edificados como espacios libres exteriores o interiores, $u$ otras estructuras significativas, definiendo los componentes naturales que lo acompañan. A los elementos singulares se les dispensará una protección integral, y a todos los demás elementos se les fijará el nivel adecuado de protección.

La conservación del Conjunto comporta el mantenimiento de la estructura urbana y arquitectónica y de las características generales de su ambiente. Se deben mantener las alineaciones urbanas existentes y solo excepcionalmente un Plan podrá permitir remodelaciones urbanas.

El artículo 23 que ordena que no se den licencias para obras que, de acuerdo con la Ley de PHE requieran autorización administrativa, y si se realizan esas obras, la Administración competente en materia de protección del PHE puede ordenar la reconstrucción o demolición con cargo al responsable de la infracción.

El artículo 36 que ordena que los bienes integrantes del PHE deben ser conservados, mantenidos y custodiados por sus propietarios y que su utilización queda subordinada a que no pongan en peligro los valores que aconsejan su conservación. Además el incumplimiento de esas normas es causa para la expropiación de esos bienes.

Como vemos la normativa es clara y rigurosa, pese a lo cual y quizá por la concurrencia de tres Administraciones, la estatal, la de 
las Comunidades Autónomas y la municipal, con demasiada frecuencia asistimos a operaciones urbanísticas o a la sustitución de edificios en los Centros Históricos que producen graves perjuicios a las ciudades o pueblos declarados, y a la oposición a que recaigan esas declaraciones de Bienes de Interés Cultural, o a ataques a los entornos indispensables para el mantenimiento de esos Conjuntos.

Todo ello se produce por el enfrentamiento de dos tipos de interés: uno a largo plazo de carácter público y otro a corto plazo y de carácter normalmente privado, aunque está demostrado que incluso desde un punto de vista económico reporta más beneficios un centro histórico o un lugar mantenido debidamente que un lugar degradado o sencillamente destrozado por la mezcla de edificaciones nuevas, hechas sin talento ni respeto. Cada día es más evidente esto y los testimonios de los ingresos por servicios de ciudades como Salamanca, Segovia, Toledo, Cáceres, etc. lo demuestran. Pero estas evidencias no pueden con el egoísmo de un propietario, la soberbia de un arquitecto, o la ignorancia o la complicidad de un político.

Por ello uno de los temas pendientes en esta materia es la capacidad y la voluntad de hacer cumplir las normas por quienes tienen ese encargo. Unas veces por la ignorancia y falta de la conciencia de los que deben respetarlas o hacerlas respetar; otros por el afán de lucro de los propietarios de esos edificios o por la falta de ayudas económicas o fiscales para que los titulares puedan mantener y renovar esos monumentos o zonas (y hay que reconocer que el legislador ha sido enormemente renuente a la hora de aplicar las medidas de fomento que anuncian las leyes o de conceder los apoyos fiscales que aconsejan los tratados internacionales) lo cierto es que se quebrantan con frecuencia las normas conservacionistas de los centros históricos y los conjuntos.

Una de las causas y quizá de las mayores de la degradación de muchos lugares, pueblos, barrios y conjuntos de ciudades es como ya hemos apuntado el mal entendimiento de los tres poderes corresponsables: el municipal, el autonómico y el nacional. Aunque la mayoría de las leyes de Patrimonio autonómicas establecen normas paralelas a la ley nacional de 1985, no faltan incumplimientos por parte de los gobiernos autonómicos y sobre todo de los municipales, problemas que se multiplican al tratar de la defensa de los entornos como en los recientes casos en la Alhambra y el acueducto de Segovia.

Todo ello nos debería hacer pensar en cuales serían las medidas necesarias o prácticas para asegurar la conservación adecuada de esas ciudades milenarias que son una riqueza para España, y un patrimonio insustituible para la Humanidad. 
Precisamente España es de los dos o tres países del mundo que más espacios tiene reconocidos como Patrimonio de la Humanidad. Toledo, Segovia, Ávila, Salamanca, Cuenca, Cáceres, Santiago de Compostela, o Alcalá de Henares tienen ese carácter y hay además Monumentos o Conjuntos que también lo comparten, como la Alhambra, la Mezquita de Córdoba etc. etc.

Podemos tomar el ejemplo de Toledo, que es una ciudad milenaria, corte de visigodos, musulmanes y cristianos, cuna de las 3 culturas, y de las más atendidas y mejor cuidadas por sus autoridades, para ver cual es su situación actual y su futuro. Toledo tiene además una colaboradora importante en la Real Fundación de Toledo.

En los últimos informes hechos por la Fundación se aprecia claramente cuáles son los problemas reales que asaltan a una ciudad histórica y qué se necesita para conservarla. Resumiendo mucho esos informes, se deduce de ellos como datos negativos:

Una reducción de la población en el casco histórico y un abandono de él por las familias jóvenes, con el consiguiente envejecimiento, a lo que se une que una cuarta parte de las viviendas del casco, no están ocupadas.

Un mal estado de conservación en casi la mitad de sus edificios que alcanza incluso a 35 monumentos declarados.

Un alto nivel de establecimientos comerciales cerrados o de baja calidad, y unas carencias importantes de equipamientos, lo que aleja a la población activa que, del casco, se traslada a los barrios periféricos nuevos.

Una falta de espacios verdes y arbolado, y unas dificultades para el tráfico rodado y para el aparcamiento, y por lo tanto una mala comunicación para los turistas y sobre todo para los habitantes de esa zona.

Todo ello implica una perdida de calidad de vida que aleja a sus habitantes del centro y con ello se corre el riesgo de vaciar de vida real esa zona y como consecuencia de quitarle la vitalidad que necesita para subsistir, no sólo como decorado sino como ciudad vivida.

En cambio por el esfuerzo de las autoridades, de las organizaciones sin ánimo de lucro como la Fundación de Toledo y de parte de sus habitantes, Instituciones y comercio:

Casi un 60\% de los edificios del casco son antiguos y el plano y la estructura viaria conservan su carácter histórico.

El casco mantiene su valor paisajístico muy bien, y la densidad y altura de las construcciones está bastante respetada. El carácter monumental está muy bien preservado, hay 115 monumentos entre todos sus barrios y el $70 \%$ de ellos están bien conservados.

El casco sigue siendo el centro de actividad de la ciudad por sus actividades administrativas (capital de la provincia y de la Comunidad) 
y económicas (centros de enseñanza, turismo, hostelería, negocios, cierto tipo de comercio); y están cuidados sus servicios públicos municipales en general, pero al mismo tiempo esto es muy positivo, Toledo es en muchos barrios y rincones silencioso y tiene una paz y sosiego que hoy es un verdadero lujo.

Este examen o estudio debería hacerse en todos nuestros Conjuntos históricos y artísticos para subsanar los defectos, acentuar las ventajas, $\mathrm{y}$ asegurar la subsistencia y la vida grata para pobladores y visitantes en todas nuestras ciudades y pueblos históricos.

Pero lo cierto es que esos análisis faltan y que la batalla entre los que queremos que las leyes se cumplan y que la sociedad asuma como propio el objetivo de mantener adecuadamente esos Conjuntos Históricos y los que infringen esas normas y olvidan o no aprecian las ciudades históricas y sus monumentos, se salda con escaramuzas en las que las victorias se reparten con el consiguiente daño para el Patrimonio Artístico e Histórico de España.

Por ello creo que son indispensables: nuevas iniciativas legislativas; una mayor y mejor educación de los ciudadanos: vecinos, propietarios, técnicos de la construcción y de las leyes, funcionarios y políticos; un respeto más riguroso de la normativa vigente, y sobre todo un mayor estimulo legislativo y económico a través de medidas de fomento eficaces y reales, que suelen faltar tanto en la ley de 1985 como en las leyes de Patrimonio de las Comunidades en las que las limitaciones a los propietarios prevalecen claramente sobre las ayudas no sólo económicas (créditos blandos y ayudas para restauración y conservación) sino también fiscales.

Como muestras recientes de esta tendencia podemos, para terminar con una visión esperanzada, una serie de casos como son: algunas normas de la Ley de Incentivos Fiscales de 1994; la redacción del articulo 4.1 y 2 de la ley del Impuesto sobre el Patrimonio de 1991, la introducción al fin, en la ley de Presupuestos del año 2000 de una reducción fiscal del 95 por 100 en el artículo 20 de la Ley Impuesto de Sucesiones que afecta a todos los Bienes de Interés Cultural y entre ellos a las casas Históricas, y unas recientes declaraciones del Director General de Bellas Artes en las que propone hacer una nueva categoría reducida de una serie de ciudades y Monumentos o Conjuntos especialmente importantes, a los que se les concederían apoyos y desgravaciones notables que aseguraran su mantenimiento y mejora en beneficio de toda la Sociedad.

Hace ya años en un artículo que escribí en1988 sobre «La financiación del Patrimonio Cultural» decía:

Desde la Declaración de Arnsterdam de 1975, la labor del Consejo de Europa para promover la conservación del Patrimonio Arquitectónico 
y Cultural Europeo, ha sido incesante y fructífera. La doctrina que han ido sentando sus acuerdos y sus recomendaciones han sido el método más eficaz para que los Estados y las sociedades europeas se hayan ido concienciando de la importancia de ese Patrimonio y de la necesidad de medidas eficaces para conservarlo.

Sin embargo, la conservación de un Patrimonio Cultural tan extenso es una complicada tarea agravada por dos circunstancias: la frecuente falta de sensibilidad de muchos poderes públicos y fuerzas sociales, y la insuficiencia de recursos para atender a las costosas tareas de conservación y restauración. El progreso de las sociedades europeas y la mayor demanda cultural, unido al esfuerzo del Consejo, ha ido disminuyendo el primer obstáculo, y hoy ya es un sentimiento extendido el valor no sólo cultural, sino económico y social, de ese Patrimonio.

No obstante, el segundo problema sigue sin resolver. Los recursos dedicados a la conservación quedan aún muy lejos de las necesidades a cubrir. Ante esa realidad, el Consejo de Europa desde 1975 ha venido repitiendo en sus resoluciones y recomendaciones la necesidad de incorporar a esa tarea a todas las fuerzas sociales: poderes locales, propietarios particulares, asociaciones y fundaciones, y a la iniciativa privada. $\mathrm{Y}$ ello ha ido creando un ambiente.

Y aunque desde 1975 se había señalado la insuficiencia de los recursos públicos dedicados a estos fines hay un momento en que se produce una inflexión decisiva en este campo. Es cuando tras el Acuerdo de Granada de 1985 para la salvaguardia del Patrimonio Arquitectónico Europeo, en el que se parte de que «constituye una expresión irreemplazable de la riqueza y de la diversidad del Patrimonio Cultural de Europa, un testigo inestimable de nuestro pasado y un bien común de todos los europeos», se llega a la afirmación, en 1987 en la reunión de Sintra de los ministros de Cultura, de «la insuficiencia de los recursos, públicos para hacer frente a una demanda creciente de productos y servicios culturales», y corno consecuencia, a la necesidad de «reforzar la participación de la sociedad civil en la vida cultural».

$\mathrm{Y}$ es evidente que la clave de la bóveda sobre la que se asienta el edificio de la salvaguardia y conservación del Patrimonio Arquitectónico, es encontrar nuevas fuentes de financiación y reconocer que la sociedad civil tiene un papel indispensable, ya que sin la financiación y colaboración privada es imposible mantener ese Patrimonio.

España que tiene uno de los Patrimonios Histórico Artísticos más extensos e importantes, no sólo para la memoria de nuestra historia, sino también para el conocimiento y conservación del Patrimonio de Europa, tiene que proponerse lograr los objetivos marcados en esas 
normas o criterios internacionales. Las recentísimas reformas indicadas en las anteriores líneas de la Ley del Impuesto sobre el Patrimonio de Fundaciones e Incentivos Fiscales y del Impuesto de Sucesiones son pasos positivos que muestran un cambio de orientación, pero es preciso que las Administraciones públicas en todos sus niveles y la sociedad actúen conjuntamente para obtener los siguientes fines:

- Conseguir la concurrencia de la financiación pública y privada dejando aquella sobre todo para los monumentos de exclusiva utilización, cultural, y estimulando la financiación privada a buscar la rentabilidad por la reutilización de los edificios adaptándolos a las necesidades de hoy.

- Conciliar la conservación de los edificios antiguos, con la flexibilidad en el hallazgo de nuevos usos para ellos, para incorporarlos a la vida normal de la sociedad y coordinar la política de conservación cultural con la de vivienda y animación de los centros históricos.

- Crear los estímulos para dirigir recursos financieros de la iniciativa privada y de las empresas hacia las tareas de conservación y rehabilitación del Patrimonio Cultural, y facilitar las actividades de mecenazgo o patrocinio de las empresas y apoyar las fundaciones. Y para eso, lo más importante es una legislación fiscal que desgrave en renta la inversión en conservación o restauración de edificios históricos, las donaciones a esos fines, y establezca un trato especial en los Impuestos de Sucesiones, IVA, Patrimonio y Contribución urbana.

En resumen, se trata de unir los objetivos culturales con la rentabilidad económica, social o mixta, atrayendo las iniciativas, recursos y capacidades de la sociedad civil hacia el mundo de la cultura. Y reservar los escasos recursos públicos para los bienes de menor utilidad económica y de mayor representatividad cultural e histórica que, a pesar de su coste deben en cualquier caso ser conservados. 